\title{
CURRÍCULO ORIENTADO A COMPETÊNCIAS PARA O CURSO DE ENGENHARIA CIVIL: UM ESTUDO DE CASO
}

DOI: 10.37702/2175-957X.COBENGE.2021.3462

Kastelli Pacheco Sperandio - kastelli.sperandio@gmail.com

Centro Universitário UNIFACIG

Rua Doutor José Carlos Pires 19

36904-201 - Manhuaçu - MG

Natália Tomich Paiva Miranda - ntomich@gmail.com

Centro Universitário UNIFACIG

rua josé carlos pires 19

36904-201 - Manhuaçu - MG

Humberto Vinício Altino Filho - humbertovinicio@hotmail.com

Centro Universitário UNIFACIG

Rua Dirceu Lacerda de Castro 74

36906-255 - Manhuaçu - MG

Resumo: Com a publicação das Diretrizes Curriculares Nacionais (DCN) dos cursos de graduação em Engenharia, no ano de 2019, o Curso de Engenharia Civil do Centro Universitário UNIFACIG buscou se adequar às novas orientações. Para a reformulação do Projeto Pedagógico do Curso (PPC), foram realizadas inúmeras reuniões entre o Núcleo Docente Estruturante (NDE), Colegiado do curso de Engenharia Civil e o TEIA - Espaço de Inovação UNIFACIG. A nova proposta curricular foi construída de modo a garantir a formação técnica, bem como o desenvolvimento das competências gerais e específicas. Nesse sentido, o presente artigo tem como objetivo apresentar a construção de um currículo orientado à competências do curso de Engenharia Civil do UNIFACIG, onde professores e alunos trabalham juntos para o desenvolvimento das competências esperadas para o profissional de Engenharia Civil

Palavras-chave: Currículo orientado a competências. Diretrizes Curriculares Nacionais. Engenharia Civil. Aluno como protagonistas. 


\section{CURRÍCULO ORIENTADO A COMPETÊNCIAS PARA O CURSO DE ENGENHARIA CIVIL: UM ESTUDO DE CASO}

\section{INTRODUÇÃO}

As universidades precisam enfrentar, com coragem, a sua própria renovação. Não sabemos o que nos espera. $\mathrm{E}$, no entanto, mesmo diante do desconhecido, temos a obrigação de agir: o maior risco é não sermos capazes de arriscar. Esta transformação exige ousadia e ambição, procurar novos caminhos, construir instituições diferentes, agregar valor aos nossos alunos. Espera-se que as universidades possam se integrar à sociedade e assumir responsabilidades cívicas, caso contrário, em pouco tempo se tornarão irrelevantes (NÓVOA, 2019).

Os objetivos da educação não podem mais ser descritos por um conjunto fixo de conhecimentos especializados que são transferidos de uma geração para a seguinte. $O$ conhecimento deve ser aplicável à diferentes situações e contextos novos e complexos, dando a oportunidade ao aluno de desenvolver a capacidade de resolução de problemas, o trabalho em equipe, a liderança, entre outras tantas habilidades necessárias no século XXI (KLIEME, 2008).

Nesse sentido, o presente trabalho tem como objetivo apresentar a construção de um currículo orientado a competências no curso de Engenharia Civil e desenvolver uma reflexão sobre a necessidade de inovação no Ensino Superior. Este projeto contou com a participação de um grupo de professores do Núcleo Docente Estruturante (NDE), a Coordenação do Curso, profissionais atuantes no mercado e outros atores, sendo um trabalho de construção coletiva.

\section{REFERENCIAL TEÓRICO}

\section{O que é competência?}

A educação baseada em competências é um tópico altamente relevante na pesquisa educacional em todo 0 mundo. A competência compreende uma integração de conhecimentos, habilidades e atitudes, indicando a capacidade de realizar tarefas profissionais com segurança e ética (KLIEME, 2008). O uso do termo competência é uma consequência da necessidade de superar um ensino que, na maioria dos casos, reduziuse a uma aprendizagem cujo método consiste em memorização, isto é, decorar conhecimentos, fato que acarreta uma dificuldade para que os conhecimentos possam ser aplicados na vida real. Ser competente é, ao agir, mobilizar, de forma integrada, conhecimentos e atitudes mediante uma situação-problema, de forma que a situação seja resolvida com eficácia (ZABALA, 2015).

Vale ressaltar, no entanto, que a competência e os conhecimentos não são antagônicos, pois qualquer atuação competente sempre envolve o uso de conhecimentos inter-relacionados a habilidades e atitudes. Sem conteúdos conceituais sobre os quais aplicar procedimentos é impossível que eles sejam aprendidos de modo significativo e utilizados em qualquer situação. O termo competência representa a alternativa que supera as dicotomias: memorizar e compreender; conhecimentos e habilidades; teoria e prática, agregando todos estes conceitos para construir uma aprendizagem autêntica (ZABALA, 2015). 


\section{As competências do século XXI}

O mundo do trabalho está mudando - e alguns empregos estão mudando mais rápido que outros. De acordo com as pesquisas mais recentes, em breve, seremos tão bons quanto as habilidades que possuímos. Mas quais são essas habilidades e como podemos garantir que estamos permitindo que nossos alunos adquiram essas habilidades?

Segundo o Fórum Econômico Mundial de 2020, a Quarta Revolução Industrial nos trará robótica avançada e transporte autônomo, inteligência artificial e aprendizado de máquina, materiais avançados, biotecnologia e genômica.

Essas tecnologias transformarão a maneira como vivemos e a maneira como trabalhamos. Alguns empregos desaparecerão, outros crescerão e empregos que ainda não existem hoje se tornarão comuns. O certo é que a futura força de trabalho precisará alinhar suas habilidades para acompanhar o ritmo.

Segundo o Fórum Econômico Mundial, as principais competências necessárias na atualidade são:

1. Resolução de problemas complexos

2. Pensamento crítico

3. Criatividade

4. Gestão de pessoas

5. Colaboração

6. Inteligência Emocional

7. Julgamento e tomada de decisões

8. Orientação de serviço

9. Negociação

10. Flexibilidade cognitiva

No entanto, essas competências não nascem com o profissional. Elas se desenvolvem e se aprimoram ao longo dos anos. A resolução de problemas complexos, que consiste na capacidade de resolver problemas novos e indefinidos em ambientes reais, se constrói a partir de uma base sólida de pensamento crítico. O profissional do futuro deverá ter a elasticidade mental para resolver problemas que nunca viu antes. Os solucionadores de problemas complexos serão os profissionais mais demandados no futuro (WORLD ECONOMIC FORUM, 2020).

A criatividade se tornará uma das três principais competências. Com a avalanche de novos produtos, novas tecnologias e novas formas de trabalhar, as pessoas terão que se tornar mais criativas para se beneficiar dessas mudanças.

A inteligência emocional, que compreende a identificação de nossos próprios sentimentos, para que possamos nos motivar e gerir as emoções dentro de nós, é uma habilidade social importante para os gestores e líderes e será muito demandada em todas as indústrias do futuro. Em síntese, precisamos acompanhar o ritmo das mudanças para prosperarmos no futuro (WORLD ECONOMIC FORUM, 2020).

\section{O que é um currículo baseado em competência?}

Pelas razões descritas nos tópicos acima, nos últimos anos, observamos a necessidade da mudança do currículo centrado no conteúdo para o currículo centrado na competência, cujas principais características são: componentes moldados pelas necessidades da sociedade e aprendizagem centrada no aluno (BERGSMANN, 2015). 
As competências se referem à ação. Para defini-las e construir um novo currículo, é preciso ter como ponto de partida a análise de quem é o profissional que precisamos formar e em qual contexto ele está inserido. É preciso analisar quais são as habilidades esperadas desse profissional na sociedade, como ele pode transformar as realidades existentes e, a partir dessa análise, definir as competências (KLIEME, 2008).

Os graduados competentes são capazes de introduzir mudanças no ambiente de trabalho, conduzir uma pesquisa e influenciar mudanças na era da prática baseada em evidências. Para isso, é necessário o desenvolvimento de competências pessoais (capacidade de iniciativa, resiliência, responsabilidade e criatividade); competências sociais (trabalho em equipe, trabalho em rede, empatia, paixão); e competências de aprendizagem (gestão, organização, capacidades metacognitivas e capacidade para converter as dificuldades em oportunidades). Em um ambiente dinâmico, caracterizado por uma rápida produção de conhecimento, o currículo baseado em competências (CBC) é uma abordagem educacional para preparar esse tipo de graduado (PACHECO, 2020).

\section{METODOLOGIA}

Após a publicação da Resolução № 2, de 24 de abril de 2019, que institui as Diretrizes Curriculares Nacionais do Curso de Graduação em Engenharia, o curso de Engenharia Civil do Centro Universitário UNIFACIG buscou se adequar às novas orientações.

Para a reformulação do Projeto Pedagógico do Curso (PPC), foram realizadas muitas reuniões entre o Núcleo Docente Estruturante (NDE), Colegiado do curso de Engenharia Civil, dos quais a grande maioria dos professores são atuantes no mercado de trabalho da engenharia, e o TEIA - Espaço de Inovação UNIFACIG. A construção do novo currículo foi fundamentada na DCN de 2019, de modo a garantir a formação técnica e, principalmente, o desenvolvimento das competências gerais e específicas para os egressos do curso segundo estas diretrizes.

Inicialmente foram definidas as competências gerais e específicas que seriam contempladas em cada um dos períodos do curso. Após essa definição, as disciplinas do curso foram distribuídas entre os períodos de acordo com seus objetivos, verificando sua contribuição para o desenvolvimento das competências necessárias para aquele período. Dessa forma, tem-se o currículo orientado a competências, isto é, as disciplinas são organizadas para compor a conjuntura de conhecimentos, que juntamente com as habilidades e atitudes irão embasar o desenvolvimento das competências que são o norte daquele semestre. Além disso, foram verificadas as questões de carga horária em cada um dos períodos, realizando todos os ajustes necessários para a finalização do currículo.

\section{ANÁLISE E DISCUSSÃO DE RESULTADOS}

Segundo as Diretrizes Curriculares Nacionais (Brasil, 2019), o perfil do egresso do curso de graduação em Engenharia deve compreender, entre outras, as seguintes características: (I) ter visão holística e humanistas, ser crítico, reflexivo, criativo, cooperativo e ético e com forte formação técnica; (II) estar apto a pesquisar, desenvolver, adaptar e utilizar novas tecnologias, com atuação inovadora e empreendedora; (III) ser capaz de reconhecer as necessidades dos usuários, formular, analisar e resolver, de forma criativa, os problemas de Engenharia; (IV) adotar perspectivas multidisciplinares e transdisciplinares em sua prática; (V) considerar os aspectos globais, políticos, econômicos, sociais, ambientais, culturais e de segurança e saúde no trabalho; (VI) atuar com isenção e comprometimento com responsabilidade social e com o desenvolvimento sustentável. 
Ainda segundo essas diretrizes, o curso de graduação em Engenharia deve proporcionar aos seus egressos, ao longo da formação as seguintes competências gerais: (I) formular e conceber soluções desejáveis de engenharia, analisando e compreendendo os usuários dessas soluções e seu contexto; (II) analisar e compreender os fenômenos físicos e químicos por meio de modelos simbólicos, físicos e outros, verificados e validados por experimentação; (III) conceber, projetar e analisar sistemas, produtos (bens e serviços), componentes ou processos; (IV) implantar, supervisionar e controlar as soluções de Engenharia; (V) comunicar-se eficazmente nas formas escrita, oral e gráfica; (VI) trabalhar e liderar equipes multidisciplinares; (VII) conhecer e aplicar com ética a legislação e os atos normativos no âmbito do exercício da profissão; (VIII) aprender de forma autônoma e lidar com situações e contextos complexos, atualizando-se em relação aos avanços da ciência, da tecnologia e aos desafios da inovação. Além das competências gerais, a DCN (Brasil, 2019) ainda destaca que devem ser agregadas as competências específicas de acordo com a habilitação ou com ênfase do curso, que nesse caso é Engenharia Civil.

Em consonância com as Diretrizes Curriculares Nacionais (Brasil, 2019), o curso de Engenharia Civil do UNIFACIG tem como objetivo garantir a formação de profissionais com visão holística e humanista, com senso crítico, reflexivo, criativo, cooperativo e ético; com atuação inovadora e empreendedora, capazes de reconhecer as necessidades dos usuários e solucionar os problemas de Engenharia; que, em sua prática, adote perspectivas multi e transdisciplinares. Além disso, o curso tem como objetivo formar profissionais que considerem os aspectos globais, políticos, econômicos, sociais, ambientais, culturais e de segurança e saúde no trabalho; e que sejam isentos e comprometidos com a responsabilidade social e com o desenvolvimento sustentável. No âmbito técnico, é objetivo desse Curso de Engenharia Civil formar profissionais que estejam aptos a realizar projetos estruturais, elétricos, hidrossanitários, geotécnicos, de saneamento e infraestrutura, discutir e criar propostas para as questões urbanas, visando um egresso que seja capaz de entender a necessidade de desenvolvimento de forma contínua no campo profissional e educacional.

Sendo assim, o curso de Engenharia Civil do UNIFACIG possibilita a formação de um profissional que possa compreender a engenharia como uma possibilidade de leitura de um mundo dinâmico em constante processo de transformação. Para isso, o curso está bem fundamentado tanto no campo teórico quanto no campo prático, permitindo a formação do engenheiro com habilidades técnicas e, ainda, com responsabilidade ética, social e sustentável. Para tanto, seu novo currículo contempla disciplinas e conteúdos que visam garantir o desenvolvimento de competências, habilidades e atitudes importantes para o profissional de Engenharia Civil.

Para isso, o currículo desenvolvido para o curso foi fundamentado no desenvolvimento de competências, habilidades e atitudes específicas para cada um dos períodos, e que se complementam e possibilitam o alcance dos objetivos e do perfil desejado dos egressos. Os três primeiros períodos do curso, no geral, abrangem as disciplinas que possibilitam o desenvolvimento de habilidades básicas para a engenharia, como a análise e compreensão dos fenômenos físicos e químicos; resolução de problemas, com a formulação de soluções criativas, desejáveis e viáveis. Para os semestres subsequentes há habilidades e competências específicas para cada período, que buscam capacitar o aluno na proposição de soluções relacionadas à Engenharia de crescente complexidade, permitindo a análise e reconhecimento do terreno, elaboração de projetos rodoviário, de infraestrutura, instalações prediais, fundações, de superestrutura, construção e gerenciamento de obras.

Além das disciplinas teóricas e práticas, são contempladas cargas horárias de Atividades Complementares, Projetos Integradores, Estágio Supervisionado e Projeto Final 
de Curso. As Atividades Complementares possibilitam ao aluno a aquisição de habilidades e competências, seja no ambiente acadêmico ou fora dele, consubstanciada pela prática de estudos e atividades independentes, opcionais e interdisciplinares, que tenham relação pertinente com atividades acadêmicas, especialmente aquelas que dizem respeito às relações de trabalho e melhoria da sociedade. Já os Projetos Integradores permitem a integração horizontal, vertical, transversal e multidisciplinar, com o objetivo principal de propiciar e avaliar o desenvolvimento das habilidades e competências específicas do período em questão, além do trabalho em equipe. Além disso, são contempladas também atividades práticas reais, através do Estágio Supervisionado, e o desenvolvimento do Projeto Final do Curso, que permite aos estudantes demonstrar a capacidade de articulação das competências inerentes à formação do Engenheiro Civil.

Figura 1: Competências relacionadas ao $1^{\circ}, 2^{\circ}, 3^{\circ}, 4^{\circ}$ e $5^{\circ}$ período do curso.

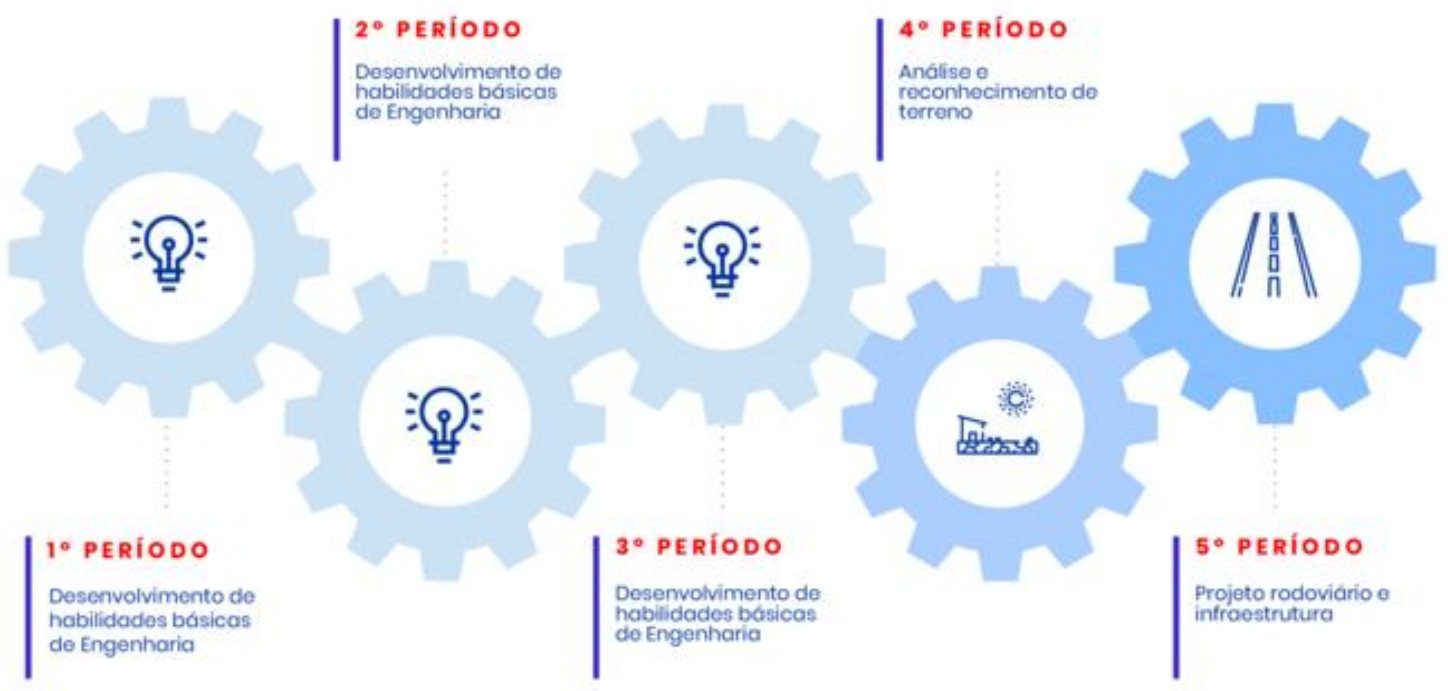

Conforme apresentado na Figura 1, para $01^{\circ}, 2^{\circ}$ e $3^{\circ}$ períodos do curso, as competências pretendidas estão relacionadas, basicamente, com o desenvolvimento de habilidade básicas de Engenharia, com a análise e compreensão de fenômenos físicos e químicos, resolução de problemas e construção de soluções criativas, desejáveis e viáveis, nos contextos propostos. Ainda nesses períodos iniciais são trabalhadas a comunicação eficaz nas formas escritas, oral e gráfica; leitura e análise de desenho técnico e projetos arquitetônicos utilizando ferramentas manuais e digitais; ciência e tecnologia dos materiais, informática, algoritmos e programação.

Para os semestres subsequentes são trabalhadas habilidades e competências específicas para cada período. Para o 4 ํㅜ período do curso (Figura 1), a competência geral é referente a análise e reconhecimento de terreno, através do desenvolvimento de habilidades relacionadas ao levantamento topográfico; análise e caracterização do solo; locação da obra no terreno; aplicação de ferramentas estatísticas para coleta de dados, inferência e tomada de decisões confiáveis; desenvolvimento de uma consciência ambiental no que tange a elaboração e execução de projetos de engenharia.

Já para o 5 o período (Figura 1), a principal competência envolve a elaboração de projetos rodoviários e de infraestrutura, através da criação de projetos geométricos de rodovia; dimensionamento da pavimentação; análise históricos pluviométricos e dimensionamento de projetos de drenagem; reconhecimento e análise das propriedades e comportamento do solo. 
Figura 2: Competências relacionadas ao $6^{\circ}, 7^{\circ}, 8^{\circ}, 9^{\circ}$ e $10^{\circ}$ período do curso.

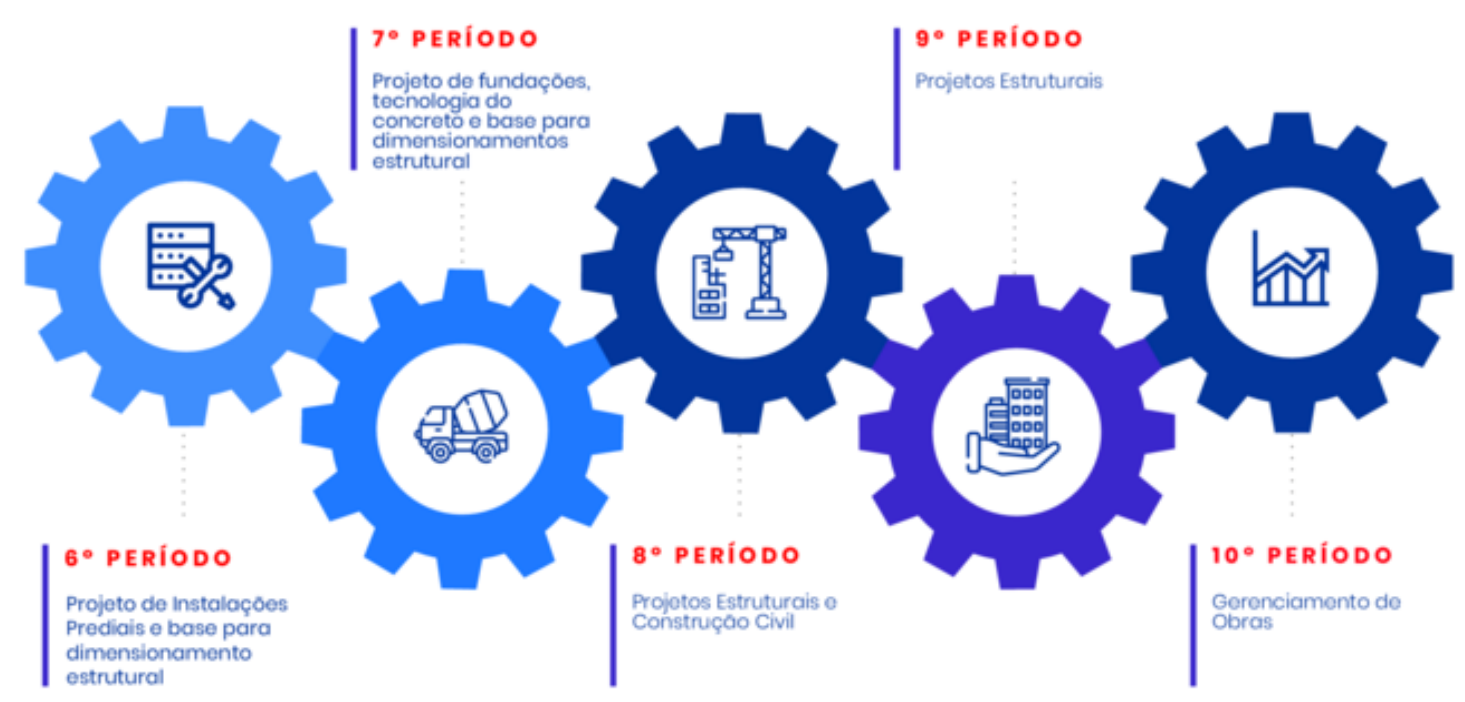

O 6ํำ período, conforme apresentado na Figura 2, tem como competência básica a elaboração de projetos de instalações prediais e base para o dimensionamento estrutural, através da elaboração e dimensionamento de projeto de instalações elétricas e hidrossanitários; compatibilização de projetos; especificação dos materiais básicos de construção e base para dimensionamento de estruturas, através da análise estrutural e resistência dos materiais.

No $7^{0}$ período (Figura 2) as competências pretendidas envolvem a elaboração de projetos de fundações e tecnologia do concreto, mantendo os conceitos fundamentais e base para o dimensionamento estrutural; através da análise dos materiais componentes, dosagem e controle tecnológico do concreto, análise de ensaios geotécnicos e dimensionamento de projetos de fundações. Já no $8^{\circ}$ período (Figura 2), as habilidades e competências estão relacionadas com a concepção de projetos estruturais e construções civis, que envolvem as estruturas de concreto armado e de madeira, análise e dimensionamento de estruturas de obras de terra e contenções; análise da implantação e execução de obras; estudo de diversos sistemas construtivos e materiais e suas interações, bem como as principais patologias das construções.

O 9 período (Figura 2), o penúltimo do curso, envolve basicamente a concepção e elaboração de projetos estruturais, através do dimensionamento de estruturas de concreto armado, estruturas metálicas e pontes; e aborda também a elaboração e escrita de textos científicos. No último período do curso $\left(10^{\circ}\right)$, conforme apresentado na Figura 2 , a principal competência trabalhada envolve o gerenciamento de obras, através do gerenciamento de projetos de construção; análise e planejamento de orçamento de obras; identificar oportunidades na engenharia e transformá-las em negócios lucrativos.

\section{CONCLUSÃO}

Com o grande avanço da tecnologia nos últimos anos, o Fórum Econômico Mundial de 2020 apontou que as principais competências necessárias para enfrentar e se destacar no mercado de trabalho, independente da área, são resolução de problemas complexos, 
pensamento crítico, criatividade, gestão de pessoas, colaboração, inteligência emocional, julgamento e tomada de decisões, orientação de serviços, negociação e flexibilidade cognitiva.

Como estas competências não nascem com o profissional, torna-se um grande papel da educação desenvolvê-las em seus estudantes ao longo dos cursos de graduação. Nesse sentido, pode-se observar uma mudança dos currículos, antes centrados basicamente em conteúdo, para o currículo centrado nas competências. Além disso, com a publicação das DCN do Curso de Graduação em Engenharia, o curso de Engenharia Civil do Centro Universitário UNIFACIG buscou se adequar às novas orientações através do desenvolvimento de um currículo orientado à competências.

O currículo desenvolvido para o curso foi fundamentado no desenvolvimento de competências, habilidades e atitudes específicas para cada um dos períodos, e que se complementam e possibilitam o alcance dos objetivos e do perfil desejado dos egressos. Além das disciplinas teóricas e práticas, também são contempladas cargas horárias de Atividades Complementares, Projetos Integradores, Estágio Supervisionado e Projeto Final de Curso, que auxiliam no desenvolvimento das competências esperadas para 0 profissional de Engenharia Civil.

Os resultados refletem a criação e organização de um currículo inovador, onde professores e alunos trabalham juntos para o desenvolvimento de competências, onde os alunos contribuem para a transformação social e construção de novas realidades e, acima de tudo, um currículo desenhado para que os alunos sejam verdadeiramente protagonistas no processo de aprendizagem.

\section{REFERÊNCIAS}

BERGSMANN, Evelyn et al. Evaluation of competence-based teaching in higher education: From theory to practice. Evaluation and program planning, v. 52, p. 1-9, 2015.

BRASIL. Conselho Nacional da Educação. Resolução CNE/CES № 2, de 24 de abril de 2019. Diretrizes Curriculares Nacionais do Curso de Graduação em Engenharia. Disponível em: http://portal.mec.gov.br/component/content/article?id=12991 Acesso em: 10 abril 2021.

KLIEME, Eckhard; HARTIG, Johannes; RAUCH, Dominique. The concept of competence in educational contexts. Assessment of competencies in educational contexts, v. 3, p. 22, 2008.

NÓVOA, António. O futuro da universidade: o maior risco é não arriscar. Revista Contemporânea de Educação, v. 14, n. 29, p. 54-70, 2019.

PACHECO, José Augusto; SOUSA, Joana; BEATRIZ, lla Beatriz. Conhecimento e aprendizagem na educação superior: desafios curriculares e pedagógicos no século XXI. Revista Diálogo Educacional, v. 20, n. 65, 2020.

WORLD ECONOMIC FORUM. Davos 2020: Here's what you need to know about the future of work, 16 Jan 2020. Disponível em: https://www.weforum.org/agenda/2020/01/davos-2020-future-work-jobs-skills-what-toknow/

ZABALA, Antoni; ARNAU, Laia. Como aprender e ensinar competências. Penso Editora, 2015. 


\title{
COMPETENCE BASED CURRICULUM FOR THE CIVIL ENGINEERING COURSE: A CASE STUDY
}

\begin{abstract}
Abstrcat: In order to adapt to the new guidelines for engineering graduation and to implement inovations in teaching and learning, our university center has created a new curriculum. For the reformulation of the Course Pedagogical Project (PPC), numerous meetings were held between the Structuring Teaching Nucleus (NDE), Collegiate of the Civil Engineering course and TEIA - na innovation space at UNIFACIG. The new curricular proposal was built in order to guarantee technical training, as well as the development of general and specific skills. This article aims to present the construction of a curriculum oriented by competences, where teachers and learners work together to develop competences and skills expected for the Civil Engineering professional.
\end{abstract}

Keywords: Competence based curriculum. National Curriculum Guidelines. Civil Engineering. Student as protagonists 